\title{
El arte de la metáfora indígena
}

\author{
Luis E. Ferro
}

\author{
Departamento de Filosofía de la Universidad de Guanajuato, México \\ c_bowaka@yahoo.com
}

Egresado de la Escuela Nacional de Antropología e Historia en el área de Antropología Social, cuenta con maestría en Filosofía en la Universidad Autónoma de Querétaro y es doctor en Ciencias Antropológicas de la Universidad Autónoma Metropolitana en México. Ha realizado distintas publicaciones relacionadas con los grupos indígenas de México: otomí y chichimeca jonaz. Actualmente es profesor/investigador del Departamento de Filosofía de la Universidad de Guanajuato, México. Sus líneas de investigación refieren a temas como: otomíes, ezar, religión, memoria, oralidad, relato, identidad, multiculturalidad, antropología filosófica y pensamiento mexicano y latinoamericano. En el 2008 obtuvo la segunda mención honorífica del Premio Nacional Wilberto Jiménez Moreno de Investigación en Cultura Regional que otorga el Instituto Cultural del Estado de Guanajuato, con el trabajo intitulado: Simbiosis Guadalupana: Historia e imagen sagrada del mundo Ezar.

Resumen: Para el mundo indígena, la memoria es palabra viva que se manifiesta en relatos que se construyen a través de las transfiguraciones de la metáfora. La metáfora es, por tanto, el eje y recurso narrativo para evocar el sentido de sus manifestaciones sociales y estéticas que nacen, ritualizan y explican con la oralidad sus propias experiencias vivenciales en el devenir del tiempo.

Palabras clave: Metáfora, memoria, oralidad, Otomíes, Chichimeca Jonaz.

Abstract: To the indigenous world, memory is alive word manifested in stories that are constructed through the transfiguration of metaphor. The metaphor is thus the axis and narrative to evoke the sense of their social and aesthetic manifestations arise, ritualized and explained the orality their own life experiences in the course of time resource.

Keywords: Metaphor, memory, orality, Otomis, Chichimeca Jonaz.

Cuadernos de Antropología 2014, 24(1): $65-76$

Recibido: 26-06-2013-2014 / Aceptado: 08-06--2014

Revista del Laboratorio de Etnología María Eugenia Bozzoli Vargas Escuela de Antropología, Universidad de Costa Rica http://revistas.ucr.ac.cr/index.php/antropologia ISSN 2215-356X

c) (i)(2) Cuadernos de Antropología está bajo una licencia Creative Commons Attribution-NonCommercial-ShareAlike 3.0 
La discusión que se presenta en el presente ensayo se generó al reflexionar sobre la relación existente entre la literatura y la antropología para el análisis del relato al partir de algunas propuestas de autores que han reflexionado sobre el tema desde la antropología, de ahí retomé la idea que afirma:

A diferencia del crítico literario, el antropólogo no se puede limitar, sino por un momento, a la autonomía de la esfera literaria. Esto no es sólo con base en la necesidad de una análisis de las funciones que cumplen los relatos en una sociedad, sino con base en los valores ontológicos que contienen, y en los cuales la cultura que los crea o los adopta están inmersos (Segre, 1990, p. 14).

Otro autor importante fue sin duda Austín (1998), quien tiene la opinión de que:

...la creación literaria: es cierto que tanto las peculiaridades de las obras literarias como los agrupamientos derivados de ellas están sujetas al devenir histórico, que pertenecen a una realidad social específica; pero también es cierto que una coincidencia de los factores de la composición y el uso social del producto literario pueden dar origen a peculiaridades que son comunes a realidades ajenas entre sí (p. 255).

Con estas premisas literarias y antropológicas se fueron develando la pertinencia del relato en su función histórica en los pueblos indígenas a través de la filosofía latinoamericana que tiene como trasfondo social y filosófico la siguiente pregunta: ¿existe una literatura que hable de lo íntimo y nos permita establecer el sentido de lo propio del sentir latinoamericano?, lo cual genera un problema ante la pregunta complementaria: ¿existe, entonces, un género literario latinoamericano que debe inscribirse como recurso de una literatura propia para el mundo? Y en contraparte: ¿cómo expresar entonces con métodos propios nuestro ser y nuestro quehacer dentro del mundo latinoamericano? Estos cuestionamientos nacen ante el problema de la oralidad y la escritura que subyace en y dentro de la narrativa indígena, cuya utilidad se ha asumido como una forma de perpetuar una resistencia cultural para mantener su identidad.

Todo ello deriva en que la literatura indígena proviene de un sentimiento y quehacer histórico-cultural, por lo que no solo es un conjunto de relatos con historia, sino que conlleva consigo el sentido de un constructo social sustentado en una práctica ubicada dentro de los márgenes de una estética oral que proviene de un sentimiento y de un quehacer histórico-cultural que no suele ser considerado para comprender nuestra propia realidad. Resulta importante resaltar que en la literatura indígena, el vencido habla desde su intimidad, en la cual, muestra una historia propia y resemantiza los textos adquiridos en su relación con el mundo, pues en este tipo de narración, el mito y el rito van inmersos en sí, porque este tipo de narraciones que se guardan en la memoria no deben ser consideradas como textos aislados de su referente social porque el mito refuerza su historia o bien, la historia se refuerza con el mito. Por lo tanto, el análisis metodológico nace con base en los fundamentos alternativos de narración de los textos indígenas que solo 
pueden ser comprendidos desde los contexto vivenciales en el que se articulan: la historia, la cultura y las dinámicas sociales en la forma de una trama que reafirma el sentimiento de pertenencia a través de las palabras de la oralidad y de la escritura.

De todo esto deviene el problema de la importancia de las acciones de la memoria y, sobre todo, nos deja la pregunta: ¿en qué momento el texto de la memoria se convierte en un objeto cultural y antropológico? Para desarrollar el tema se ha seleccionado algunos materiales que se han recabado a través del trabajo de campo y retomado de algunos textos que se encuentran descontextualizados en algunos textos; así como de artículos que tratan sobre los pueblos otomíes del semidesierto queretano y el grupo chichimeca jonaz. La elección de estos grupos como marco referencial de la reflexión del trabajo fueron elegidos por tres razones principales: la primera porque son grupos con los cuales he tenido contacto directo, y en un segundo plano, porque son dos grupos indígenas que se localizan en las fronteras entre lo que se considera como: Mesoamérica y Aridoamérica. Los primeros eran sedentarios y agricultores, los segundos eran grupos nómadas y cazadores-recolectores. Dos maneras distintas de vivir y, por lo tanto, dos condiciones culturales con historias y concepciones particulares del mundo, lo que permitía establecer un contraste en la construcción de los textos narrativos de su quehacer histórico y aun siendo historias diferentes en esencia mantienen el mismo sentido de manifestar, estructurar y simbolizar sus narraciones, convirtiéndose en una manera de hacer historia desde una propia intimidad que se aleja de las especificaciones científicas heredadas de occidente sin dejar de ser historia, demostrando de esa manera al pensamiento latinoamericano la posibilidad de escribir y narrar la historia de nuestro mundo con otras metodologías, métodos y procesos. De esa manera nace este ensayo.

El universo es un esplendor que nace de múltiples sucesos que aún siguen produciéndose en una infinidad de regiones cósmicas que lo conforman. El ser humano ha nacido entrópicamente en una de estas regiones cósmicas para ser parte de la continuidad del gran suceso que otorga vida al movimiento universal. Dentro de los múltiples sucesos del universo, estamos aquí, antropólogos historiadores y literatos o algún filósofo extraviado con la finalidad de pensar, reflexionar, repensar, construir y reconstruir las ideas de una historia y de un quehacer literario que den cuenta de ese suceso llamado humanidad, a través de los tiempos y las declinaciones de las palabras. Sin embargo, a literatos, historiadores, filósofos y antropólogos nos une la palabra y es la intención de ella misma la que nos separa.

La palabra es el sentido y la expresión del ser humano, pero ¿cómo encontrar nuestro sentido humano en las palabras? ¿Cómo escribirlas y cómo contarlas para encontrar el sentido de lo que somos? Los cabalistas buscan en las palabras el espíritu, los historiadores en el objeto mismo de la historia en su verbo pasado, los literatos en el arte de la poesía, en las bellezas de las palabras y desde las locuciones de la vivencia. Aun así, todas estas maneras de acercarse a las palabras que dan sentido al ser humano conforman una expresión para dar cuenta de una imagen del mundo y una manera de representar al ser humano en ese mundo, y así construir la historia que nos represente como sujetos, como pueblo y como humanidad, pero ¿qué acontece al crear las palabras que enuncian el espíritu, la poesía, la vivencia y la historia del sujeto en el mundo? 
¿Quién puede detener a las palabras en la ejecución de su sentido? ¿Quién es el que mantiene entre sus manos el acto de narrar, el qué piensa o imagina un acto tras bambalinas, o aquél que interpreta e improvisa la obra en el momento de su representación? ¿Quién es el narrador de la historia? ¿Quién hace del cuento, la historia de "colorín colorado este cuento se ha acabado", o quién es el dueño del "érase que se era"? ¿En dónde se encuentra el orden de las palabras que han de ser narradas y contadas? ¿Quién lee las palabras? ¿Quién escribe los sentidos de las palabras? ¿A quién le corresponde la palabra? ¿Quién es dueño de la historia que se cuenta? Y por último ¿a quién le corresponde definir qué es historia y qué no lo es?

Las palabras al narrar la historia se vuelven acciones, trasmutaciones y movimientos. Son sonidos que ritualizan los sentidos de lo que se dice, lo que se piensa y lo que se hace:

Para concebir la sociología del conocimiento hay que concebir por tanto, no sólo el enraizamiento del conocimiento en la sociedad y la interacción conocimieto/ sociedad, sino sobre todo el bucle discursivo por el que el conocimiento es producto/productor de una realidad sociocultural, la cual comporta intrínsecamente una dimensión cognitiva (Morin, 2001, p. 25).

De tal manera, las palabras permiten comprender al universo, al mundo, nuestro mundo y nuestra historia. Las palabras, por tanto, ayudan a configurar la geometría de una realidad social, histórica, poética y espiritual de quién la pronuncia.

La palabra no solo se escucha, también se observa y se siente. La historia es sentimiento y es pasión. La palabra es de quien la porta y la que nos ubica en el mundo. La palabra en consecuencia es la esencia del ser humano que con su aliento vital la pronuncia, la crea y la transfigura para hacer girar el mundo de lo humano. El ser humano acciona la palabra haciendo girar el mundo porque las palabras al ser articuladas, y por decir más de lo que dicen, generan un lenguaje, un tiempo y un espacio que materializan la expresión de pensar al mundo, de esa forma encierra a la realidad en una elíptica y laberíntica metáfora que tiene dentro de sí las infinitas posibilidades de narrar, relatar y contar el tiempo y los sucesos de las realidades y fantasías humanas.

El ser humano volcó la experiencia de su tiempo en la búsqueda eterna de su autobiografía, de esa manera es una experiencia del tiempo, y como resultado de esto, es producto del tiempo y de su tiempo.

Lo que distingue al ser humano es la facultad humana que le permite contar y relatar historias que nacen de engarzar palabras en el marco general de un sistema simbólico, de una lógica que da sentido y transformación del habla en un lenguaje que se organiza en el encuentro con lo propio y lo ajeno, al mundo con el resto de la humanidad y al ser humano consigo mismo. El relato, así visto, es una experiencia y una estética de ser, porque el ser humano al narrar da cuenta de sí y su en sí; el arte de contar es experiencia 
que habla, que es pensada y es materializada en acciones sociales que dan coherencia a la memoria que resurge en palabras para dar cuenta de su realidad, así la existencia del ser humano se posesiona del texto de su propio contexto, porque:

El fenómeno de la posesión se revela capaz de recapitular la historia de todos detallando la de cada uno de nosotros: una arqueología ideal que propone, mediante el espectáculo de los cuerpos poseídos, la imagen de la copresencia simultánea de pasados diferentes, imposible al único universal (Augé, 2007, p. 31).

El ser humano con esta acción narrativa revierte el orden y la continuidad del tiempo, juega con el presente en tres estados, el ahora, el ayer y el mañana, tiempos que se socializan en tres formas: el momento del ahora, la memoria y la esperanza. En esta socialización, ordena el mundo y da continuidad al mundo al que se pertenece. La pertenencia se orienta en el ser humano ante el deseo, porque el tiempo social es el tiempo de narrar una manera de percibir y experimentar el tiempo social y generar en el espacio donde se vive la materialización de la narración del mundo social que es narrada para construir el movimiento de una estética de ser y saberse ser a través de la memoria para determinar al mundo al que se pertenece.

Así nos encontramos humanos que estudian humanos, seres humanos que piensan seres humanos, humanos que narran seres humanos y humanos que se narran así mismos, esa es la consecuencia de una historia y una literatura del sujeto cuando se convierte para sí en una historia de narración. Desde que surge la palabra y la intención de contar historias, el mundo se simboliza, con el evocativo del mundo, se narra y nace el sujeto humano con sus propios cuentos y sus propias historias. Somos la continuidad de un instante que perdura por el tiempo del recuerdo y del acto de narrar una memoria inconclusa que nos centra en el escenario propio de los espacios de una armonía práctica dentro de una narración, el tiempo social y el espacio es el texto en donde nos identificamos con los tiempos gramaticales del verbo que miran hacia la vivencia del saberse ser, tal y como lo comenta Lynch (1987), quien afirma que existe un: "[...] inveteradoarte de producir y consumir relatos [...]". Por otra parte, Marinas (1994) nos menciona que existe: "[...] la necesidad de explorar la intimidad, como escenario [...] en que las formas de identificación tiene una repercusión y un alcance propios". Sin embargo, cabe preguntar desde esta parte del mundo ¿cuál es nuestra producción y consumo de relatos? Y ¿cómo se configura la intimidad que genera nuestros escenarios?.

El pensamiento occidental ha puesto en beneficio de la duda nuestra alma y nuestro espíritu, nos ha impuesto un nombre, un concepto de ser humano y nos ha impuesto un dios. Los europeos se afirman así mismos como una cultura y civilización original y, por ende, se observan como seres humanos originales, Morin (2003) asienta que: "Europa [es] una civilización original, marcada por la espiritualidad, el humanismo, la racionalidad, la democracia, es decir virtudes y valores superiores a los de cualquier civilización." Ese pensamiento de superioridad ha llevado a Europa a considerarse con derecho de anteponer 
su humanidad al resto de la humanidad, con este acto antepone su razón como única visión del mundo y una sola forma de conducirse en el análisis de la historia e impone la manera de hacer literatura, negando la posibilidad de alcanzar la intimidad de nuestros escenarios, y nos ciega en la manera de contar nuestra historia, porque la civilización occidental siempre trata de imponer sus sistemas, teorías y pensamientos, haciéndonos olvidar nuestra propia estética de ser, de ahí que Guy Rozat (2002, p. 14) llegue a plantear:

Queda así por resolver el problema de saber si en un discurso producido y controlado durante siglos por Occidente habrá lugar para la mínima verdad americana, o si se quiere: ¿cómo se puede rastrear, en el conjunto de textos e imágenes que constituye América como representación occidental, los elementos de una genuina y preservada América de antes del contagio con Occidente?.

Pregunta difícil de contestar, pero abre horizontes de una búsqueda a la pregunta; sin embargo, con la pregunta queda marcado que somos otra cosa, una cosa que no podemos definir porque no hemos encontrado el camino de esa definición, de nuestro propio relato y nuestro propio escenario que nos ubique en una historia de narración, lo cual produce en Latinoamérica, un sujeto ambiguo y, por lo tanto, el cuento de una historia con un gran vacío de expresión, y ello nos dirige a que debemos encontrar la lógica de lo que nos hace relatar el contexto, el tiempo y el espacio de lo que somos; es decir, debemos como latinoamericanos encontrar las formas que den cuenta de nuestra intimidad a través de la palabra, la historia y la literatura.

Tal vez la respuesta de la lógica que se está buscando se localiza en el mundo indígena, aunque ante la ambigüedad del sujeto indígena que se encuentra en los relatos escritos por los primeros cronistas, se está ante un problema para el análisis del discurso porque no se puede definir con precisión de qué indio hablamos; si del indio muerto o vivo, del indio real o imaginario; sin embargo, la solución es posible encontrarla en el contenido y la forma de la estructura narrativa y la manera en que el mundo indígena relata y construye sus historias porque van más ligadas a un ámbito literario lleno de metáforas y subjetividades, más que de hechos o procesos históricos pensados desde los conceptos occidentales. El relato indígena por estar compuesto por un cúmulo de metáforas que explican su vivencia y su historia indígena, se le niega valor y la posibilidad de que las palabras autóctonas sean consideradas como una historia sistematizada y científica, ( si es que se considera a la historia como una ciencia). Tan solo llegamos argüir que la historia indígena por solo hecho de ser indígena es una historia (con minúscula), negada por regodearse de palabras mágicas, limitadas por el mundo del tabú, y llena de bellas alegorías y llenas de una estética del mundo platicado con la más fina literatura. Nuestra incapacidad de confrontar esa otra manera de concebir del quehacer histórico limita nuestra propia percepción del mundo porque no podemos descifrar sus más elocuentes significados de los relatos indígenas plagados de metáforas, por lo que, la oralidad y la lógica que da sustento a la palabra indígena se menosprecia por no contar con el talente de la razón y el argumento occidental. Lo que acontece es que no podemos asimilar que la historia y la literatura indígena están engarzadas, porque ambas dan cuenta de una representación del mundo y es la forma en que han percibido 
una manera de entenderse en el mundo, construyendo su propia manera de hacer historias de narración; por eso, la historia indígena nos trastoca, pero no sabemos cómo integrarla como parte de nuestra historia y una forma de hacer historia. No podemos explicar su comprensión y reafirmamos que forma parte de nuestro horizonte cultural, lo presumimos, lo estudiamos, lo trasmitimos, lo transcribimos; no obstante, su sentido siempre es oculto a la mirada y al pensamiento occidental, porque no hemos aprendido apreciar el cómo participar en la comprensión y esclarecimiento de esas palabras que armonizan su propia historia y su pensamiento; de esta forma, la historia indígena cuenta con un sistema de narración particular. Tenemos miedo de aceptar una historia fomentada por la metáfora porque no explica claramente la realidad de manera "objetiva" o real de los acontecimientos; mientras tanto, ellos se posesionan de las metáforas como la expresión real de las vivencias de su tiempo social. Aquí ya no importa cómo se hace la historia, sino cómo se construye en profundidad esa historia, o esa otra manera de hacer historia. Cómo convergen las palabras para generar los enunciados del texto que tienden a narrar y resguardar en la memoria.

La historia indígena por lo que se ha establecido se vuelve metáfora y se acerca a la literatura, a un mundo razonable donde la intención de la palabra que se articula en un lenguaje propio no está en la verdad, ni en la racionalidad, sino que existe en la visión del mundo y su tiempo. Su razón de ser se localiza en los puntos de la emoción y la sensación que demuestra su existencia en las orillas de su tiempo social, por lo que el mundo indígena es un mundo concebido en lo público por las condiciones históricas en que se ha sometido al compartir sus propios tiempos estructurados con metáforas ajenas a su propio lenguaje. Este mundo del que hablamos vive del tiempo dialógico de lo privado y de lo íntimo en donde no busca el sentido del condicional, sino el contenido de la vivencia:

En este contexto, todo significado es construido bajo condiciones de posibilidad de su propia interpretación. Todo sentido es entonces intercambiable, y toda interpretación es fractal, es decir, a la vez repetible y generalizable, a la vez autónoma y relacionada con un contexto específico (Zavala, 2006, p. 28).

Así planteado, no es el proceso histórico lo que define la historia indígena, sino la cotidianeidad y sus repeticiones, por forma en que se hace manifiesto su existencia y la sensibilidad que se tiene en torno a la vivencia y lo cotidiano. Estos ingredientes generan la expresión de la lógica de su historia relatada bajo aspectos literarios, más que literales de su propia manera de emancipar su mente y su memoria en una historia de narración. El suceso histórico, en este caso, se fractaliza en la repetición y el reflejo de su propio mundo en donde cosmovisión, cosmogonía y ethosson se vuelven un solo sentido en el relato de la vida indígena. Una vida de autogénesis y de exégesis ha sido su fundamento de creación histórica.

Los grupos indígenas pueden vivir sin esa historia instrumentada por occidente porque es ajena a sus propios métodos de transmisión de su verdadera historia, por lo que la historia occidental es sustantiva. Para los indígenas, las palabras y las metáforas que configuran su historia son verbo, acción, presencia y persistencia, no hay categorías científicas y negaciones en su formulación teórica, tan solo se platica y es suficiente sostenerla con la oralidad y su reproducción oral, ya lo afirma Certau (1996): "Si el arte de decir 
es en sí mismo un arte de hacer y un arte de pensar, puede ser a la vez su práctica y su teoría.” Entonces, si cada pueblo tiene la expresión de su tiempo, tiene en sus manos su teoría en el arte de su existencia ¿Cuál es el tiempo narrativo de los grupos indígenas en la historia, su historia y sus historias? Como veremos con ejemplos de los chichimecas jonaz y otomíes, la historia es contada y reafirmada con la metáfora y la alegoría, por lo que su historia se sustenta en la manera literaria de contarla.

En las historias indígenas, las palabras no expresan el sentido, ritualizan el significado, de ahí que los chichimecas jonaz describan desde su propia narración el orgullo chichimeca como parte de su identidad, lo hacen pensando en sus antepasados, tal y como Jaime Martínez, músico de un grupo musical de Misión de Chichimecas, trasmite con sus propias palabras el imaginario ancestral:

Para mí era más o menos como de uno noventa, inclusive hasta de dos metros. Muy fornido, atlético también. Moreno de tez; bueno hay dos logotipos de nariz, una poco ancha y otros de nariz afilado como aguileña. Los más morenos, los guachichiles esos sí eran hasta azules. Buenos y ágiles para cazar (entrevista oral, 2008).

Aunque en la oralidad registrada en un libro de narraciones se menciona que: "Los gigantes eran como unos palos, pero cuando caían ya no se podían levantar por lo delgado que eran vivían en cuevas" (Chavero, 1995, p.11). Sea cual sea el caso, estos antepasados se materializan en la danzas de guerra vestidos de taparrabos y rostros pintados. Mientras que su historia es ritualizada en la fiesta de San Luis Rey en donde utilizan al santo como metáfora histórica para recordar el tratado de paz con los españoles y la tregua con los otomíes que lucharon al lado de los españoles. La Virgen de Guadalupe, otro de los santos reconocido por los chichimecas, sufre también los efectos de esta lógica y reitera un territorio que les pertenece; además, es la santa que los proveyó de su idioma, mientras que el águila les brindo el entendimiento, y del cual el cronista novohispano de descendencia chichimeca Fernando de Alva (2000) hace mención en sus narraciones sobre las naciones chichimecas: "Y este apellido y nombre de chichimeca lo tuvieron desde su origen, que es vocablo propio de esta nación, que quiere decir los águilas, y no lo que suena en la lengua mexicana..." (p. 26). De esa manera, esta ave se convierte en un tótem inconsciente que les provee de un encuentro con su origen.

La sacralidad de la historia indígena arrastra tras de sí a su gente, y a personajes de la historia. Una niña de origen chichimeca llamada Patricia Quevedo (1995, p. 13) narra lo siguiente:

Mi escuela se llama Chupitantegua. ¿Quién fue Chupitantegua? Fue un jefe chichimeca que se conoce en el año 1552. Él no era majurrú, pero era valiente como él. Cuando lo nombraron jefe, juntó a todos los grupos chichimecas para pelear. Él 
peleó contra quién querían quitarle las tierras...Los cerros del Meco fueron incendiados, porque era el lugar que les servía de refugio. Las tribus de la sierra gorda fueron vencidas. Les quitaron la tierra y la libertad. Nosotros somos los que hemos quedado como hijos de Chupitantegua.

Entre tanto en Juventino Rosas Guanajuato, recuerda que Pancho Villa salvó al pueblo de un fusilamiento masivo por parte de los ejércitos del gobierno y por tal gesto las personas lo transfiguraron en la forma de un santo católico al cual se le rinden un culto de agradecimiento en una capilla de origen otomí. Así, a diferencia de los chichimecas, los otomíes del semidesierto queretano, los antepasados se vuelven relatos familiares que se materializan en las animitas que son pinturas con motivos católicos que muestran el árbol genealógico de la familia, con la finalidad de no olvidar el origen, y que en su sentido más profano y cotidiano doña Alicia (comunicación oral, 2005) comenta: "Aquí los Martínez no existían, llegaron [...]", y el hecho de afirmar llegaron se desata de la memoria la historia de una familia y cómo fue que llagaron a la microregión otomí de Sombrerete. Un origen que se refuerza en la vida otomí cada 2 de noviembre cuando en el panteón se les habla a las nuevas generaciones de las personas de la familia que se encuentran enterradas ahí. La palabra y la manera de remembrar a los seres queridos hacen nacer el recuerdo a la filiación familiar a la que se pertenece en formas de relatos íntimos, y la tumba es llevada alegóricamente a la casa en la forma de un altar de muertos en donde se les reza y se les prenden veladoras para brindar luz a los antepasados familiares. En ese ritual, cada veladora es una persona familiar fallecida; y cuando la luz se extingue rápido, es necesario ofrecerle un novenario para que no sufra el antepasado en los umbrales de la muerte. Para aquellas almas de los antepasados que han sido olvidadas en la relatoría familiar, los otomíes de Sombrerete Cadereyta, en un rincón de la casa, colocan atole y sal para las ánimas olvidadas. De ahí que el espacio del hogar se transfigura, es sombra y es de paso, por ello le llaman sombrita a la casa, y la verdadera casa se encuentra en el panteón donde las tumbas siguen el esquema de la familia extensa porque se entierran lo más cerca posible, porque en este lugar otomí parece que los muertos no deben olvidar su origen familiar y hacen constar que los muertos no están realmente muertos. La sombrita otomí se reinventa, une a la vida, a la muerte y al tránsito de la existencia individual y colectiva. En el hogar se entierra el cordón umbilical del recién nacido en el solar; si es mujer, lo más cercano a la cocina para que no se olviden del hogar y siempre reconozcan su origen familiar, no es tan solo un rito de paso, es el inicio de una relatoría, una historia de marcar la pertenencia y la continuidad de la historia del grupo al que el recién nacido ha de incorporarse.

Por otra parte, Sombrerete se llama así porque se reconoce en su espacio físico un cerro con forma de sombrero. Misión de chichimecas se llama así porque fue una misión de chichimecas, San Miguel Tetillas en Querétaro porque se apareció San Miguel Arcángel en uno de dos cerros que semejan unas tetas. La palabra y el arte de nombrar y ritualizar es una oralidad profunda; cuando falta la oralidad, la ritualidad 
explica las palabras olvidadas, como el caso del Xitá, personaje ritual enmascarado de las tierras de Sombrerete, del cual se ha olvidado el mito de su historia; sin embargo, manifiesta con su presencia en los días de carnaval y el convite la persistencia de una historia olvidada, mientras que el sistema de cargos con los nombres de los mayores que son Madre Mayor y Mayordomo, los cuales dan cuenta de la familia originaria de un lugar que afirman esta sostenida por los cuatro ángeles de los que habla la Biblia y son cuatro comunidades las que dan sentido a la microregión de Sombrerete. Tanto el Xitá y los mayordomos se dirigen durante las festividades a los calvarios donde afirman se encuentran enterrados los antepasados para pedir agua. Estas acciones unifican una historia que se inserta en la vida del pueblo en la que el ciclo de cultivo, el ciclo festivo y las actividades agrícolas de autoconsumo conforman el cuerpo de explicación de la propia continuidad del grupo.

Cuando las fiestas y los personajes rituales desaparecen, parte de las historias de los grupos indígenas se pierde de su mundo; no obstante, con lo hasta aquí dicho, la palabra es figura y de por sí fuente de ideas; y en el mundo indígena, la palabra hecha figura se consagra como una metáfora material para recordar la historia, como es el caso de la cruz del puerto de Calderón donde se reúnen los otomíes de San Miguel Allende en Guanajuato para conmemorar la batalla y la aparición de la Santa Cruz, en donde, en un escrito que distribuyeron para hacer vales, el sentido de sus fiestas y el baluarte de su historia al pueblo mestizo de la ciudad de San Miguel de Allende, expresan lo siguiente: "[...] en la tradición oral, la cruz apareció en el cielo durante una batalla entre otomíes y chichimecas bárbaros, el día 29 de septiembre de 1531, después de una contienda que había durado dos semanas" (Correa, 2006, p. 161). Este acto conmemorativo representa para Correa (2006):

[...] la batalla y aparición de la cruz funciona como factor integrador social y religioso de esta zona. Sirve como base de una identidad común que liga a los actuales participantes directamente con los ancestros fundadores, quienes fueron conquistadores y colonizadores en esta zona fronteriza (p. 161).

La palabra en la figura de la Cruz de Calderón es algo más, nos afirman Cervantes y Crespo (1999, p. 10) que: "La cruz es asimismo, para los indígenas, un marcador simbólico del territorio ritual." Por lo cual la palabra indígena en su historia connota al territorio. Esto no es del todo así, ya que en el sentido del relato este es un pasaje histórico que no tan solo se recuerda, se rememora, se reivindica al confundirse el pasado con el presente, porque la palabra histórica indígena no solo es oralidad también se teatraliza y se dramatiza haciendo que la palabra cobre presencia como parte de la historia, por lo cual, las palabras de la oralidad indígena se separan de las representaciones de occidente, adquieren otra tonalidad y otro sentido de expresión, la palabra histórica se ritualiza para fundamentar los sentimientos de su ser, no se lee ni se dicta en libros, ya que para ellos:

http://revistas.ucr.ac.cr/index.php/antropologia 
...los encuentros de las danzas con la Santa Cruz del puerto de Calderón en el antiguo camino de la Carrera (hoy camino de la estación), donde piden perdón a la Santa Cruz por las ofensas. Y piden su ayuda y bendición para ellos y sus familiares: pidiéndose también perdón entre ellos por las rencillas y ofensas que pudiera haber (Correa, 2006, p. 163).

Aquí la ofensa refuerza el remanente del sentido más que el hecho histórico mismo, la ofensa es el eje rector de las historias de narración indígenas, por lo que la historia indígena implica un sentimiento que es negado en la manera de hacer historia en Occidente.

Muchas historias, rituales, transfiguraciones y palabras del mundo indígena pueden mencionarse, lo que aquí se ha intentado es demostrar que si partimos de la idea de que la palabra es sentido, no queda más que preguntarnos ¿cuál es el sentido de las palabras en la historia y la literatura indígena? La palabra al ser narrada se convierte en historia, y la historia se hace literatura cuando es contada. La historia es un acontecimiento, es una memoria, es un recuerdo, es la construcción de los sujetos que cuentan una historia. Y cada historia es el contar un acontecimiento.

En el mundo indígena, la historia es la que se establece en la memoria. Su literatura se une por estética en la ritualización y teatralidad de las palabras. Su historia es la literatura de su vivencia y de esta forma la palabra oral es dueña de quien la pronuncia. Esa es su fuerza y su vitalidad.

La palabra en el mundo indígena no solo se escucha, también se observa y se siente. La palabra en su sentido histórico en el mundo indígena da consonancia al orden del universo y a la situación humana que les permite expresar su sentimiento de ser. En el mundo indígena, la palabra cuenta y relata sus historias y su literatura con la oralidad de una memoria desbordada y vívida, por lo que la historia que se relata en ese mundo es vivencial y metafórico. La metáfora es su sustento, por lo que en este trabajo se ha intentado dar cuenta de que en el mundo indígena sus historias son vivencias y metáforas del orden y el sustento de una identidad y de un sentimiento de pertenencia.

El panorama que se nos presenta, entonces, es amplio porque cada sujeto es la articulación de sus palabras, acuña con sus palabras su esencia y orienta su mundo; así cada pueblo tiene en su haber sus propias entonaciones, la articulación de sus sonidos y sus palabras. La palabra es usanza y andanza que se vuelca en el relato; cada pueblo a su memoria, a sus olvidos y a sus propias conjugaciones en el universo humano y social. Cada pueblo configura su esencia y sus propias manifestaciones para hacer del mundo su mundo y son muchas las lógicas de hacer historia. El mundo indígena de México, con su forma de narrar, relatar y contar las historias de su mundo, da cuenta de que la historia puede ser construida desde la metáfora, y 
es la metáfora entonces un posible punto de inicio para contar nuestra propia historia, una historia que nos defina, porque a fin de cuentas los latinoamericanos somos una metáfora viva en pos de su propia historia.

\section{Referencias bibliográficas}

Augé, M. (2007). El oficio del antropólogo. España: Gedisa.

Austín, L.A. (1998). Los mitos del Tlacuache. México: UNAM.

Certau, M. (1996). La invención de lo cotidiano. México: Universidad Iberoamericana/Instituto Tecnológico y de Estudios Superiores de Occidente/ Centro Francés de estudios Mexicanos y Centroamericanos.

Cervantes, B. y Crespo, A.M. (1999). Fiesta y tradición en San Miguel de Allende. México: Editorial La Rana.

Chavero, M.R. (1995). Los gigantes. En: Instituto de la Cultura del Estado de Guanajuato (ed.), Narraciones chichimeca-jonaces. México: Editorial La Rana.

Correa, M. (2006). El mito de origen de los otomíes de del río Laja en el estado de Guanajuato. Estudios de Cultura Otopame, 5, 161-182.

De Alva, F. (2000). Historia de la Nación Chichimeca. España: Dastin.

Ferro, L.E. (2005). La verbalización de lo sagrado. México: Normal Superior de Querétaro/Gobierno del estado de Querétaro.

Ferro, L.E. (2006). El xitá y los ensueños de un relato. Seminario de historia mexicana, 3, 39-58.

Lynch, E. (1987). La lección de Sherherezade. España: Anagrama.

Marinas, J.M. (1994). La intimidad narrada. En M.T. López (ed.), Figuras del logos (pp.165-204). España: Fondo de Cultura Económica.

Morin, E. (2001). El método (las ideas). España: Cátedra.

Morin, E. (2003). Pensar Europa. España: Gedisa.

Quevedo, P. (1995). Chipintantegua. En: Instituto de la Cultura del Estado de Guanajuato (ed.), Narraciones chichimeca-jonaces (p. 13). México: Editorial La Rana.

Rozat, D.G. (2002). Indios imaginarios e indios reales. México: Editorial Universidad Veracruzana/Instituto Nacional de Antropología e Historia.

Segre, E. (1990). Metamorfosis de los sagrado y lo profano. México: INAH.

Zavala, L. (2006). La precisión de la incertidumbre. México: Universidad Autónoma del Estado de México. 